\title{
Epistemological Self-Confidence in Human Factors Research
}

\author{
Sidney W. A. Dekker \\ Lund University \\ Leonardo da Vinci Laboratory for Complexity and Systems Thinking \\ Sweden \\ sidney.dekker@tfhs.lu.se \\ James M. Nyce \\ Department of Anthropology \\ Ball State University \\ Muncie, IN 47306 \\ USA \\ jnyce@bsu.edu \\ Roel van Winsen \\ Lund University \\ Leonardo da Vinci Laboratory for Complexity and Systems Thinking \\ Sweden \\ roel.van-winsen@tfhs.lu.se
}

Eder Henriqson

Pontifícia Universidade Católica do Rio Grande do Sul

School of Aeronautical Science

Brazil

ehenriqson@pucrs.br 


\section{Epistemological Self-Confidence in Human Factors Research}

Abstract. A recent conversation in the literature asks whether human factors constructs amount to folk modeling or to strong science. In this paper we explore this further in the context of well-known positions on the production of science and scientific rationality. We inquire about the sources of epistemological self-confidence-the extent to which human factors is satisfied with its beliefs and assumptions about how it knows what it knows. We question whether a large body of evidence for a construct is evidence of strong science, or whether critical reflection and skepticism about this is actually what distinguishes scientific knowledge from folk models. We also review presumptions of a-perspectival objectivity, in which researchers believe they are able to take a "view from nowhere" and enjoy an objective window onto an existing reality. We ask whether human factors constructs don’t so much reflect but rather create a particular empirical world, which would not even exist without those constructs. This article serves as an invitation to rethink what we mean by epistemological confidence and how we arrive at it.

Keywords. human factors, epistemology, folk models, methods, objectivity, philosophy 


\section{Introduction}

Parasuraman, Sheridan and Wickens (2008) continue a conversation following Dekker and Woods (2002) and Dekker and Hollnagel (2004). At issue was whether some constructs developed by and used in the field of human factors represent "folk models" that substitute one large label for another (e.g. “overconfidence” for “complacency”), and that are unfalsifiable and easily overgeneralized. Parasuraman et al. (2008) offer evidence of a large science base of empirical studies with well-operationalized constructs that yield objectively verifiable data—all of which would suggest the contrary.

The present article is a further invitation to this conversation by framing it in terms of more fundamental beliefs about science, and what we call "epistemological confidence" — the extent to which we in human factors are satisfied with our beliefs and assumptions about how we know what we know. Parasuraman et al. (2008) try to provide evidence for the scientific status of some human factors performance constructs. In this article, we place this epistemological confidence in the context of well-known positions of authors like Kuhn, (1962), Foucault (1980), Gould (1981), Althusser (1984), Latour (1987), the Gulbenkian Commission (Wallerstein, 1996), Feyerabend (1993) and others.

The point of this not to assess whether human factors' epistemological confidence is justified as that would, in the limit, demand some kind of outside adjudication, which itself would raise issues of credibility and legitimacy (see Kuhn, 1962; Latour, 1987). Rather, our goal is to try to excavate what for human factors practitioners are central assumptions of thought and practice—-beliefs that researchers more often assume than discuss or critique (for an exception, see Xiao \& Vicente, 2000). Assumptions about the nature of a field's epistemological confidence can be difficult to bring to the surface. But they do form a tacit 
consensus that is reinforced and further validated in the work of a field; they inform what researchers count as evidence and what they feel confident calling science.

The two main claims to epistemological confidence that Parasuraman et al. (2008) refer to are: (a) the large base of empirical human factors data and (b) the idea that researchers can access objective states of the world

\section{More Empirical Support Means Better Scientific Constructs}

Parasuraman et al. (2008) believe that constructs such as situation awareness, mental workload, and trust in automation are not folk models but are rather viable and empirically supported. They “... show that the constructs can be operationalized using behavioral, physiological, and subjective measures, supplemented by computational modeling” and refer to "... the large science base of empirical studies on these constructs” (p. 140). Of course, all scientists routinely derive epistemological confidence from the fact that other people have found similar things about a construct used in the field, or that results about a construct produced through different methods seem to point in a similar direction. But taking this as a chief source of epistemological certainty can lead to overconfidence. Unquestioned confidence in such accumulation of constructs and evidence can in part be the result of accepting an epistemology legitimated by the paradigm — which itself generated both the demand for the data and the criteria by which evidence is defined.

The extensive literature on the philosophy of science (e.g. Kuhn, 1962; Latour, 1987; Feyerabend, 1993) suggests precisely this. That a construct is able to deliver facts about its own existence (along however many lines of evidence) may not be sufficiently persuasive. As Parasuraman et al. (2008) point out, most human factors constructs can be supported by an ample empirical record. But facts (or any scientific "evidence”) could be available in part 
because the constructs themselves constitute the facts. The danger here is that we can confuse empiricism with scientism or methodolatry.

Take situation awareness as example. Researchers cannot look for level-2 situation awareness or believe that they intervene there if a theory or model has not postulated it beforehand. Similarly, researchers who apply a theory of naturalistic decision making will not be looking for the location or workings of a decision executive in the human information processing system, but instead treat decision making as a continuous control task, a flow of mutually coupled actions and assessments and the embedding of memory (for recognitionpriming) in the situation rather than exclusively in the mind (e.g. Hoffman \& Yates, 2005; Orasanu \& Connolly, 1993).

The Kuhnian position is well known: facts exist by virtue of a current paradigm and always privilege their own paradigm. Feyerabend (1993) called all observed facts “ideational.” The so-called autonomy principle, he said, is false; facts do not have a life of their own "out there,” waiting for us to discover them. "On closer analysis, we even find that science knows no 'bare facts' at all, but that the 'facts' that enter our knowledge are already viewed in a certain way and are, therefore, essentially ideational” (Feyerabend, 1993, p. 11). From this point of view, whatever counts as data for either cannot exist without an interpretive fore-structure. Without some kind of construct, the data would not be there at all. This is captured in Klein’s “data-frame” theory of sensemaking, a general theory of how people make sense of situations, which emerged in the human factors specialization of Naturalistic Decision Making (Klein, Phillips, Rall, \& Peluso, 2007).

In short, an accumulation of empirical facts about a construct cannot be taken at face value as a validation of the scientific value or strength of the construct. Kuhn (1962) explicitly warned scientists to not make that leap. 
In any discipline, "legitimate” methods emerge from an epistemological consensus; an often implicit agreement about the kinds of apparatus and procedures one can use to get to know things, validated by a community of researchers and practitioners. Like in many other fields of inquiry, these assumptions remain largely unexamined and closed to inquiry because as safety work precisely they are so self-evident and common-sensical. The way they get retained and reproduced is akin to what Althusser (1984) called “interpellation.” For example, in cognitive task analysis, methods and constructs to analyze cognitive activity intend to help researchers and practitioners seek and explain their results in terms of those methods and constructs. Studies using the same kind of approach are then reproduced across different domains, and in doing so, gain scientific status by empirical replication. The more data, the stronger the validation of both method and constructs.

An even stronger validation of a construct, from which researchers can derive additional epistemological confidence, can be arrived at when various methods can converge upon the same construct:

... over the past half century, the concept of mental workload has been supported by strong science. On one hand, workload can be related to various measures of brain and autonomic system activity ... At the same time, converging evidence from performance, physiology, and subjective ratings has validated the construct, generated testable hypotheses, and, most important, provided useful science-based solutions to workers in a variety of endeavors. (Parasuraman et al., 2008, p. 147)

Interpellation suggests that scientists seek and explain their results in terms of the dominant constructs. Those constructs form the categories by which mainstream human factors journal submissions are divided (e.g. some of the major topics covered in human 
factors - attentional processes, cognitive processes, psychomotor processes, human error, situation awareness), by which university classes are taught, and professional specializations are defined. Researchers will also most likely make sense of their own work using those constructs; in this way, they will reproduce the existing order in their words and actions.

Parasuraman et al. (2008, p. 154) “... can confidently state that empirical studies supporting the SA, workload, and trust constructs are numerous (in the hundreds). Quantity is not everything, of course, but the vast majority of the empirical research is of high quality.” For sure, the position that we can derive epistemological confidence from a steady flow of research results that affirm their own constructs, and that such research is of high quality relative to internally agreed criteria, is seen as legitimate and common sense by most. But at least a part of such "regimes of truth" (Foucault, 1980) are established and maintained by confluences of relationships, shared discourses and institutional constraints-factors that the quantity and quality of our results can blind us to.

\section{Researchers Can Access And Represent Objective States Of The World}

The second source of epistemological confidence invoked by Parasuraman et al. (2008), and indeed by some of the literature to which they refer, is that researchers have a possibility to access and represent the objective state of the world, and that they can thus really know what is going on there. Cognitive engineering and human factors research strategies are often founded on the belief that an operator's understanding of the world can be contrasted against (and found more or less deficient relative to) an objectively available state of that world. Take situation awareness, for example. The way in which knowledge about situation awareness is legitimatized by human factors experiments, for instance, is that: 
... there is a "ground truth" against which its accuracy can be assessed (e.g., the objective state of the world or the objective unfolding of events that are predicted). (Parasuraman et al., 2008, p. 144)

Normative imposition is basic to any error assessment, of course, where:

... actual behaviour is described in terms of some kind of deviation, that is, error, with reference to the normative behaviour. (Rasmussen, 1997, p. 200)

The belief that is instantiated and reproduced here is that there is a world that is objectively available and apprehensible. This epistemological stance represents a kind of aperspectival objectivity. It assumes that we, as researchers, are able to take a "view from nowhere” (Nagel, 1989), a value-free, background-free, position-free view that is true (the "ground truth”).

Certainly, operational definitions of measures (whether these are believed to be objective or subjective) are a necessary part of the scientific process. But the human factors literature manifests a deeper belief. A research report can assert that the measures were operationalized and objective, or were "behavioral," and then continue on the assured consensus that the results to be presented constitute good science.

This re-affirms the classical or Newtonian view of nature (an independent world exists to which we as researchers, with proper methods, can have objective access) and rests on the belief that observer and the observed are entirely separable. Discussions of this in the philosophy of science are extensive (e.g., Nagel, 1986; Rorty, 1986). Among the considerations are the fact that even for so-called objective measures, subjectivity is involved in the actual application of the methodology. Furthermore, many in social science (and for 
the last hundred years, natural science too) no longer hold to the pure objectivist view. In fact, the inseparability of observer and observed has since been a common theme in some of the most acute analyses of both the social and natural sciences (e.g. Wallerstein et al., 1996). The observer is not just the contributor to, but in many cases the creator of, the observed. If there is a purely objective world, then how we could know it?

A position of "objectivity," also contains norms and prescriptions with which researchers can claim, on the basis of their knowledge, that they can adjudicate an operator's "truth.” This may be unproblematic until we realize what gets lost. Critical studies of error counting (Hollnagel \& Amalberti, 2001) showed how an error count could achieve its end only by erasing its true subject: adaptation and expertise expressed by practitioners. Postcount interviews revealed how actions or "omissions" previously rated as errors were explained by practitioners as for example anticipation of workload fluctuations. If we adjudicate an operator's understanding of an unfolding situation against our own "ground truth,” we may learn little of value about why individuals saw, what they did, and why taking or not taking action made sense to them.

\section{Confidence In The Objective Reality Of Constructs And Quantification}

The belief in objective, measurable, stable, observer-independent constructs is a strong source of epistemological confidence in human factors. Jones and Endsley (1996) illustrate this nicely. They assessed the Aviation Safety Reporting System (ASRS) database using the term "situation awareness" to tabulate the types of situation awareness errors that occur in aviation. They found that $76.3 \%$ of the errors were level 1 SA, $20.3 \%$ were level 2 SA and 3.4\% were level 3 SA. According to the authors, 
... the results give an indication of the types and frequency of SA errors that occur in aviation, with failure to monitor or observe available information forming the larger single category. Many other casual factors are also indicated, however, including vigilance, automation problems, and poor mental models. (p. 507)

That such work can lead to quantifiable conclusions (e.g. numbers of SA errors) is an operation that seems to yield objective statements from which human factors derives additional epistemological confidence. At least in contrast to, say ethnographic studies of human performance (e.g. Hutchins, 1995), human factors researchers may not feel as comfortable with language as a device for relating the results of their observations. Quantification of human factors research results reinforces the belief in the existence of an observer-independent reality: the quantified results are an objective window into it:

The use of figures and graphs not only embodies numbers, but gives the reader the sense of 'seeing the phenomenon.' By using figures and graphs the scientist implicitly says, "You don’t have to take my word for it, look for your self. (Gergen, 1999, p. 56)

What is finessed here is what the numbers "stand for" to begin with, how they were arrived at, and most significantly, what they might possibly be hiding. Validation and certainty, and thus epistemological confidence, is reduced to a kind of ranking or numerical strength, a sort of tyranny of numbers. In effect, the operationalization of a research design is equated with counting, inventorying, or classifying. In turn, these operations are equated with 
the construction of strong epistemological statements about the world, the production of facts and science.

That said, this is not unique to experimental or laboratory studies. The literature on ethnographic methods also typically pursues authenticity and some form of objectivity in the description of its empirical encounters with the world. Ethnographic texts ask the reader to accept that the researcher was indeed present in the field and grasped how insiders understood their world. Ways to achieve this authenticity include particularizing everyday situations in that world (capturing a level of empirical detail that would not have been possible without that field work, cf. Nemeth, Cook, \& Woods, 2004), and the delineation of the relationship between researcher and informant (i.e. where the perspective of one ends and that of the other begins) as well as qualifying any personal biases that the researcher may have brought to the field (Golden-Biddle \& Locke, 1993). These strategies appeal to some achievement of objectivity, to a separation between the observer and what was observed, and thereby invoke the notion of a world apart from the researcher (even if the perception onto that world by other people, the insiders, is all that the researcher can gain access to).

Perhaps the clearest example of this comes from the study of decision making, and in particular the evaluation of performance by studying the "hit rate” of judgments or decisions. One example of a hit rate in human factors, of course, is the tabulation of errors in cockpits, something that was described as researchers having perfected new ways way to monitor pilot performance (Croft, 2001). A "hit rate" of observed behavior was also included in more ethnographic studies of practitioners' adaptations to new technology in for example cockpits (Björklund, Alfredsson, \& Dekker, 2006) and operating theaters (Cook \& Woods, 1996), which increased the fit of the studies' results with human factors' epistemological preoccupations. A large literature of research in the field of judgment and decision making is built upon this, but one must ask, what is missing if all one studies about decision making is 
the hit rate of final judgments? The hit rate paradigm is largely blind to the richness of knowledge and reasoning.

\section{Constructs As True Pictures Of The World}

Seeing a hit rate, or the scientific construct behind counting hits, as a picture of the world-as-it-is, is a classic mechanistic position on science and epistemology. Here, the job of a scientist (or of the operators we study, for that matter) is to create representations or constructs that mimic or map the world. When these facsimiles do not match "reality," it is due to limitations of an operator's perception, rationality, or cognitive resources (e.g. mental workload). For researchers, this is due to limitations in our methods of observation (Flach, Dekker, \& Stappers, 2008). Naturally, this position fuels the belief that more data (more lines of evidence, more innovative experiments) means better science: better copies, better facsimiles.

But "what counts as reality is, for any particular item, at least potentially a matter of consensus and disputation” (Edwards, Ashmore, \& Potter, 1995, p. 39). Our constructs could create what we see as much as they reflect what we see. Knowledge (expressed in language, constructs) shapes, or constructs the world in ways that both facilitates and constrains action (Healy, 2003). The construct, then, is more than a construct; it is an interpretive framework that defines what constitutes observation and fact and defines the link that exists between fact and observation.

Take memory as an example. Constructs of what memory is and how it works have historically been inscribed on metaphors derived from the technology of the period, ranging from wax tablets and books to photography, telephone switchboards, and computers and even holograms. As the metaphor changed, so has thought about memory (Draaisma, 2000; see 
also Leary, 1995; Hoffman, Cochran, \& Nead, 1990). Similarly, the information processing metaphor, dominant in human factors in the 1970's (Neisser, 1976; Hollnagel \& Woods, 1983) turned attention into a phenomenon of storage and retrieval. As technological developments (wax tablets, transistors, computers) influence our models and language, we change the way we think about and therefore how we study memory or attention. Constructs, and the word we use to express them are choices, consensual agreements, for how to see the world. A technical vocabulary of constructs creates a particular empirical world, and would exist differently with other words. It is consensus that cements word to world (Gergen, 1999). This robs words (or constructs) of any inherent claim to truthfulness in the sense of describing the world as it is. That said, realism as an ontology is not at odds with, or necessarily exclusive of, a notion of epistemological relativity. If it is accepted that there is a reality that exists independently of the mind, it is still easily argued that our descriptions of it reflect a consensus and are shaped by our language and constructs.

As Parasuraman et al. (2008) pointed out, new technology enables such different languages and consensus to enter our operationalization of constructs (e.g. eye-point-of-gaze and brain imaging technologies both open up new possible empirical windows on people's “awareness”). The use of such experimental apparatus helps fix their legitimacy as practices that produce knowledge and keep knowledge in circulation. Foucault (1980) called this an epistemé: a set of rules and conceptual tools for what counts as evidence. Such practices are of necessity exclusionary. They function in part to establish distinctions between those statements that will be considered true (or factual) and those that will be considered false (or speculative, folk). For example "low situation awareness" is a language we accept as scientific to denote a mental state, while "losing the bubble" is a statement we leave to practitioners. We explicitly and implicitly agree that we can operationalize (and thereby measure) one and not the other. With one, we can derive some degree of epistemological 
confidence because we believe that we are not just reporting a subjective experience. Operationalization and our attempts to insure accuracy and validity of a measurement affirm that our scientific constructs are truer pictures of the world than what practitioners could arrive at. The true statement is circulated through the literature, reproduced in publications that underpin what is taken to be valid knowledge in our field.

Yet human factors research probably does not wish to over-privilege the notion that language alone (through metaphor and technological development) brings scientific constructs into being, nor that social consensus alone legitimates either a construct or the method by which data for it is gathered. In fact, human factors reveals a more ambiguous position. It is one that allows constructs to be influenced by both social construction and discipline stability (tradition). Writing about emotion, for example, Hoffman, Waggoner and Palermo (1991) see how:

\begin{abstract}
Although emotional experience is rich and varied, new emotions do not appear every day: the range of emotional experience is constrained (but not strictly limited) by the environment and by our evolution in it, and hence by our physiological and psychological characteristics (p. 179).
\end{abstract}

Emotion, in other words, has aspects of a stable and describable set of phenomena but also is negotiable and context-dependent. Emotions are contingent, local and particular, dependent on observer and description at the time, but they are also seen to reside in essential features of human beings (their physiological and psychological characteristics). The emotions we describe in our research are not just pictures of the world-as-it-is, but nor are they completely the contingent, historical product of an observer either: they, it is believed, contain something essential that remains constant over time. It is this ambiguity, this 
instability, in human factors' embrace of its constructs, that will keep the conversation about the field's epistemological self-confidence animated for the foreseeable future.

\section{Conclusion}

Raising the question of the scientific status of human factors, as the conversation continued in this paper does, seems to mean asking whether human factors is, or can become a "normal" science, in essential ways like the natural sciences. Most fields of scientific inquiry want to emulate the ideal of physical science, where detached scientific observation and experimentation generates facts that are objective, time- and observation-independent, and value-free, and where a steady accumulation of such facts means ever more powerful science. To the question "Why has human factors not achieved this ideal?” (as was asked by Dekker \& Hollnagel, 2004), there are at least two possible answers (Flyvbjerg, 2001), which in some sense represent the logical endpoints of the arguments discussed in this paper:

The Pre-paradigmatic Answer. Human factors is still a young science and there is nothing, in principle, to prevent it from becoming a "normal" science in the future. It has not been persuasively demonstrated, after all, that it is impossible for human factors to achieve the rigor and objectivity of the "hard" sciences. It just takes more time, and more evidence. In the pre-paradigmatic view, it is natural, or hard science that lies at the core of any field's scientific identity. Hard science functions as a kind of index against which any other field's epistemological confidence gets ranked. But, of course, even hard science has been relativized through what has been called the "universality of hermeneutics" (e.g. Feyerabend, 1993). Hermeneutics, the study of interpretation, is no longer linked only to the study of humans, but to all sciences. Even natural sciences are now seen as historically conditioned and human-constructed (Wallerstein, 1996). They too must constantly re-assess what 
constitutes relevant facts, methods and theories, and what counts as "nature.” Interpretation in human factors involves tacit practical skills and conventions acquired through training, and reinforced through the possibilities afforded by the field's professional categories, constructs and publication outlets. This leads to the other end-point: the hermeneutic answer.

The Hermeneutic Answer. Giddens (1984) argues that the study of human activity must be based on people's situational self-interpretation. Human factors is an activity in which humans study humans. Humans are self-reflecting actors, not objects in the natural world that do not answer back. For Giddens, this involves a double hermeneutic. First there are self-interpretations among those people who are studied in human factors research. Recall the Hollnagel and Amalberti (2001) study on "human error" and that people who were the object of that study disagreed with that interpretation of their performance. The second hermeneutic applies to the human researchers themselves, who are of course constituted in a particular context that offers a particular set of constructs and methods and techniques.

In the Jones and Endsley (1996) study, for example, interpretation governs both the reporters' reflections on their own performance (the description of the errors they committed and reported in their choice of words in the ASRS system) and the researchers' subsequent classification of those errors. The findings reported in the study, says Giddens, are only as stable as those two interpretations. They have no trans-historic truth values that can progress towards a greater accumulation of facts or "science.”

It could be argued that none of this matters. After all, human factors is a field born out of pragmatic concerns, not some a pre-occupation with science or philosophy. As long as human factors is able to produce tangible results, better displays, better work environments, we should perhaps not care about the extent to which it is "science," by whatever criteria. Parasuraman et al. (2008) make this argument for situation awareness, about which there is now a "substantial body of research pointing to its utility" (Parasuraman et al., 2008, p. 144). 
However, utility should not be confused with science (see also Hoffman \& Defenbacher, 1993). When it comes to utility, Kuhn (1962) warned against assuming that our constructions represent the most accurate, or most "useful" representations of what is going on. There in fact could be something silently repressive, something exclusionary, about practices that valorize the accumulation of empirical evidence for existing constructs, about practices that prioritize the quantification of research results, which re-assert the existence of an observerindependent reality. This, at worst, could blind us to the need to reflect on the nature of our own practices and belief. This kind of self-reflection is necessary because in the end it is what distinguishes scientific knowledge from folk knowledge.

Over the past decade, the deepest inquiry into the epistemological beliefs of human factors seems to have been on the question of whether methods and results produce something of quality and value. An example of this would be the continuing discussion of the need to integrate cognitive systems engineering into systems engineering, so that technology procurements do not fail (e.g., Bisantz, et al., 2002; Cooke \& Durso, 2007; Hoffman, Neville \& Fowlkes, 2009). Inquiry about the epistemological assumptions of human factors creates additional questions, especially about the ways that researchers entering the field have been educated. In human factors education, and psychology education more broadly, there seems to have emerged in recent decades a general lack of coverage in the areas of history of psychology and philosophy of science. In conversations with colleagues and students, the authors have consistently found that degree programs are becoming less likely to require courses in history. This leads to reinvented wheels, illustrated by the lack of historical scholarship in discussions of SA with regard to the longer history of the psychology of attention. The conversation of which this article is one installment raises the question about the extent to which human factors (undergraduate, but especially graduate) education is a largely instrumental exercise in the inculcation of paradigmatic assumptions 
and the application of techniques, and whether the concomitant results are usable by industries and enterprises.

\section{References}

Althusser, L. (1984). Essays on Ideology. Translated by B. Brewster and G. Lock. London: Verso Books.

Bisantz, A. M., Roth, E., Brickman, B., Gosbee, L. L., Hettinger, L., \& McKinney, J. (2002). Integrating cognitive analyses in a large-scale system design process. International Journal of Human-Computer Studies, 58, 117-206.

Björklund, C., Alfredsson, J., \& Dekker, S. W. A. (2006). Shared mode awareness in air transport cockpits: An eye-point of gaze study. International Journal of Aviation Psychology, 16, 257-269.

Cooke, N. J., \& Durso, F. (2007). In the aftermath of tragedy: Cognitive engineering solutions. Boca Raton, FL: CRC Press.

Croft, J. (2001, July 16). Researchers perfect new ways to monitor pilot performance. Aviation Week and Space Technology, pp. 76-77.

Cook, R. I., \& Woods, D. D. (1996). Adapting to new technology in the operating room. Human factors, 38, 593-613.

Croft, J. (2001, July 16). Researchers perfect new ways to monitor pilot performance. Aviation Week and Space Technology, pp. 76-77.

Draaisma, D. (2000). Metaphors of memory: A history of ideas about the mind. Cambridge, UK: Cambridge University Press.

Dekker, S., \& Hollnagel, E. (2004). Human factors and folk models. Cognition, Technology, and Work, 6, 79-86. 
Dekker, S. W. A., \& Woods, D. D. (2002). MABA-MABA or abracadabra? Progress on human-automation coordination. Cognition, Technology, and Work, 4, 240-244.

Draaisma, D. (2000). Metaphors of memory: a history of ideas about the mind. Cambridge, UK, New York: Cambridge University Press.

Edwards, D., Ashmore, M., \& Potter, J. (1995). Death and furniture: The rhetoric, politics and theology of bottom line arguments against relativism. History of the Human Sciences, 8, 25-49.

Feyerabend, P. (1993). Against method ( ${ }^{\text {rd }}$ ed.). London: Verso Books.

Flach, J. M., Dekker, S. W. A., \& Stappers, P. J. (2006): Playing Twenty Questions with Nature: Reflections on Quantum Mechanics and Cognitive Systems. Technical Report 2006-04, Lund University School of Aviation, Sweden.

Foucault, M. (1980). Truth and power. In C. Gordon (Ed.), Power/Knowledge (pp. 80-105). Brighton: Harvester.

Flyvbjerg, B. (2001). Making social science matter: Why social inquiry fails and how it can succeed again. Cambridge, UK: Cambridge University Press.

Gergen, K. (1999). An invitation to social construction. London: Sage Publications.

Giddens, A. (1984) The Constitution of Society: Outline of the Theory of Structuration. Berkeley, US: University of California Press.

Golden-Biddle, K., \& Locke, K. (1993). Appealing work: An investigation of how ethnographic texts convince. Organization Science, 4, 595-616.

Healy, S. (2003). Epistemological pluralism and the 'politics of choice'. Futures, 35, 689701.

Hoffman, R. R., Cochran, E. L., \& Nead, J. M. (1990). Cognitive metaphors in the history of experimental psychology. In D. Leary (Ed.), Metaphors in the history of psychology (pp. 173-209). Cambridge, England: Cambridge University Press. 
Hoffman, R. R., \& Deffenbacher, K. A. (1993). An analysis of the relations of basic and applied science. Ecological Psychology, 5, 315-352.

Hoffman, R. R., Neville, K. N. \& Fowlkes, J. (2009). Using cognitive task analysis to explore issues in the procurement of intelligent decision support systems. Cognition, Technology, and Work, 11, 57-70.

Hoffman, R. R., Waggoner, J. E., \& Palermo, D. S. (1991). Metaphor and context in the language of emotion. In. R. R. Hoffman, \& D. S. Palermo (Ed.) Cognition and the symbolic process. (pp.163-184). Hillsdale, NJ: Lawrence Erlbaum.

Hoffman, R. R. \& Yates, J. F. (July/August, 2005). Decision(?)-Making(?). IEEE: Intelligent Systems, pp. 22-29.

Hollnagel, E. \& Amalberti, R. (2001). The emperor's new clothes: Or whatever happened to "human error"? In S. W. A. Dekker (Ed.), Proceedings of the $4^{\text {th }}$ International Workshop on Human Error, Safety and Systems Development (pp. 1-18). Linköping Sweden: Linköping University.

Hollnagel, E., \& Woods, D. D. (1983). Cognitive systems engineering: New wine in new bottles. International Journal of Man-machine studies, 18, 583-600.

Hutchins, E. (1995). Cognition in the wild. Cambridge, Mass.: MIT Press.

Jones, D. G., \& Endsley, M. R. (1996). Sources of situation awareness errors in aviation. Aviation, Space, and Environmental Medicine, 67, 507-512.

Klein, G., Phillips, J. K., Rall, E., \& Peluso, D. A. (2007). A data/frame theory of sensemaking. In R. R. Hoffman (Ed.), Expertise out of context: Proceedings of the 6th International Conference on Naturalistic Decision Making. Mahwah, NJ: Lawrence Erlbaum \& Associates.

Kuhn, T. S. (1962). The structure of scientific revolutions. Chicago: University of Chicago Press. 
Latour, B. (1987) Science in Action. Milton Keynes: Open University Press.

Leary, D. E. (Ed.) (1995). Metaphors in the history of psychology. Cambridge, UK: Cambridge University Press.

Nagel, T. (1989). The view from nowhere. Oxford, UK: Oxford University Press.

Neisser, U. (1976). Cognition and reality: Principles and implications of cognitive psychology. San Francisco: Freeman Press.

Nemeth, C. P., Cook, R. I., \& Woods, D. D. (2004). The Messy Details: Insights from Technical Work in Healthcare. In C. P. Nemeth, R. I. Cook, \& D. D, Woods (Eds.), Special Issue on Studies in Healthcare Technical Work, IEEE Transactions on Systems, Man and Cybernetics - Part A, 34, 689-92.

Orasanu, J. M., \& Connolly, T. (1993). The reinvention of decision making. In G. A. Klein, J. Orasanu, R. Calderwood, \& C. E. Zsambok (Eds.), Decision making in action: Models and methods (pp. 3-20). Norwood, NJ: Ablex.

Parasuraman, R., Sheridan, T.B., \& Wickens, C.D. (2008). Situation awareness, mental workload and trust in automation: Viable empirically supported cognitive engineering constructs. Cognitive Engineering and Decision Making. Journal of Cognitive Engineering and Decision Making, 2, 140-160.

Rasmussen, J. (1997). Risk Management in a Dynamic Society: a modeling problem. Safety Science, 27, 183-213.

Ribot, T. (1890). Psychology of attention. Chicago: Open Court.

Rorty, R. (1991). Objectivity, relativism and truth. Cambridge: Press syndicate of the University of Cambridge.

Wallerstein, I. (Ed.) (1996). Open the social sciences: Report of the Gulbenkian Commission on the restructuring of the social sciences. Standford, CA: Stanford University Press. 
Xiao, Y., \& Vicente, K. J. (2000). A framework for epistemological analysis in empirical (laboratory and field) studies. Human factors, 42, 87-101. 